\title{
Normalized Thermodynamic Model for Intermittent Energy Systems and Application to Solar-Powered Adsorption Cooling Systems*
}

\author{
Onur Taylan ${ }^{1}$, Derek K. Baker ${ }^{2 * *}$, Bilgin Kaftanoğlu ${ }^{3}$ \\ 1,2 Department of Mechanical Engineering, \\ Middle East Technical University, 06531 Ankara, Turkey \\ E-mail: ${ }^{1}$ otaylan@metu.edu.tr, ${ }^{2}$ dbaker@metu.edu.tr \\ ${ }^{3}$ Department of Manufacturing Engineering, \\ Atilim University, 06836 Incek, Ankara, Turkey \\ E-mail: ${ }^{3}$ bilgink@atilim.edu.tr
}

\begin{abstract}
A new normalized model is developed to quantify and explore trends in coincidence of supply and demand in generic intermittent energy systems as key design and operating parameters are varied. This novel model is applied to seasonal-transient simulations for a solar-thermal powered adsorption system with and without heat recovery to investigate the coincidence between the solar-supplied cooling power and cooling load in terms of seasonal solar and loss fractions. Additionally, the system's basic performance trends are investigated as a number of parameters are varied. Results for the conditions explored include the following. The solar fraction increases and the loss fraction decreases with increases in storage capacity, and both fractions decrease with increases in maximum bed temperature. The required evacuated tube collector area is smaller than the flat plate collector area while the required mass of adsorbent is independent of collector and adsorption cycle types. Simulation results also show the effects of operating conditions and several design parameters on the system's COP.
\end{abstract}

\section{Keywords: Adsorption cooling; coincidence; demand; normalized model; smart grid; supply.}

\section{Introduction}

Turkey, like other developing countries, has a rapidly growing demand for energy in general and electricity specifically. In 2007, approximately $81 \%$ of Turkey's electricity demand was met by thermal sources (coal, lignite, fuel oil and natural gas) of which $61.2 \%$ was natural gas (TEİAŞ, 2007). Most of these fossil fuels were imported, which raises concerns over energy security. The remaining $19 \%$ of Turkey's electricity demand was met by domestic hydro, geothermal, wind, and other resources. According to the Turkish Electricity Transmission Corporation's projections (TEİAŞ, 2009), under one scenario, electricity demand will exceed supply in Turkey in 2016-2017. To meet this growing electricity demand while increasing energy security and decreasing the emission of greenhouse gases, Turkey would like to increase the share of renewable energy sources such as wind and solar. However, wind and solar resources are inherently intermittent while the demand for many energy services varies temporally. When the energy source and demand do not coincide temporally within an energy system, system reliability can be improved by using backup energy sources with high availability (e.g., fossil fuels), or technologies that shift the time of demand (load shifting), control the demand (demand side management), or store energy during times of excess capacity to be used during times of excess demand. Ultimately, energy technologies that can either supply energy services during peak demand or can reduce the peak demand are much more valuable than technologies that supply energy services or reduce the demand for energy services at non-peak times (Jebaraj \& Iniyan, 2006; Lenzen, 2010; Myers, Klein, \& Reindl, 2010). Therefore when considering an energy system with an intermittent source, variable demand, storage, back-up or load control technologies, an initial study exploring the temporal coincidence of supply and demand as the size and type of various components varies can give valuable information about the viability of the system.

The need for new technologies, models, and data to support the wider use of intermittent energy systems is reflected in recent research. The assessment of renewable resources such as solar and wind on both a temporal and spatial basis continues to be an active area of research (Ibrahim, Ilinca, \& Perron, 2008; Korpaas, Holen, \& Hildrum, 2003). More recently, research and development of smart grid technologies to control and shift demand for electricity is becoming increasingly popular (Battaglini, Lilliestam, Haas, \& Patt, 2009; Moslehi \& Kumar, 2010). While technologies that store energy on large scales or for very long time periods exist, they have not gained widespread market penetration due to various barriers. Research into these technologies continue (J. Baker, 2008) and examples of these technologies include batteries (Divya \& Østergaard, 2009), latent thermal storage (Sharma, Tyagi, Chen, \& Buddhi, 2009), sensible thermal storage (Cruickshank, 2009), compressed air (Lund \& Salgi, 2009), pumped hydro (Manolakos, Papadakis, Papantonis, \& Kyritsis, 2004), and hydrogen (Kélouwani, Agbossou, \& Chahine, 2005). Research into the impact of renewable energy systems on peak electricity demand (Benitez, Benitez, \& van Kooten, 2008; Knob, Rüther, Jardim, \& Beyer, 2004; Koomey \& Brown, 2002) and the optimization of energy systems with storage (Denholm \& Margolis, 2007; Duic \& da Graça Carvalho, 2004; Korpås,

\footnotetext{
* This paper is a revised and extended version of a paper published in the ECOS'09 proceedings and is published here with permission from the conference organizers.
} 
2004; Vosen \& Keller, 1999) exist. These studies tend to present results from or models for a particular installation.

The present work intends to contribute to this existing body of knowledge by presenting a new normalized model to study the effect of relative component sizes on the performance of energy systems with intermittent sources and variable loads. To a large extent this normalized model is technology independent and therefore is general and appropriate to study a wide range of energy systems. This newly-introduced normalized model is then applied to study the feasibility of a solar-thermal powered adsorption cooling (SPAC) system. SPAC systems are an important emerging alternative to traditional cooling technologies based on the vapor-compression refrigeration cycle. Vaporcompression refrigeration cycles typically consume electricity (which, depending on how the electricity is generated, can impact energy security, resource depletion, climate change, and pollution), make a significant contribution to peak electricity demand, and may use refrigerants that contribute to climate change and ozone depletion. Conversely, since the primary energy input to a SPAC system is solar energy rather than electricity and the refrigerants used are often environmentally benign, SPAC systems can avoid many of the problems associated with vapor-compression refrigeration.

\section{Models}

Within this study, a new general normalized model to study intermittent energy systems is introduced. The normalized model is based on discretizing some time period of interest into a series of small time steps, and studying the transient performance of an energy system consisting of an intermittent supply, variable demand, finite storage and back-up as it steps through these time steps over the time period. Although demand control technologies such as load shifting are not treated explicitly in this model, within the context of this model if these technologies move demand earlier they are equivalent to storage.

This normalized model is then applied to analyze the performance of a SPAC system modeled using TRNSYS (The Transient Energy System Simulation Tool). The TRNSYS model of the SPAC system has two main subsystems: adsorption cycle and solar-thermal system. In the following sub-sections, the individual models and how they are integrated are discussed.

\subsection{Normalized Model}

The new normalized model depends on transient, seasonal, and size parameters. The transient parameters are defined at each time step $t_{i}$. The First Law of Thermodynamics for any intermittent energy system can be given over time step $\left(t_{i}\right)$ as

$$
\mathrm{E}_{\mathrm{F}}\left(t_{i}\right)+\mathrm{E}_{\mathrm{B}}\left(t_{i}\right)=\mathrm{E}_{\mathrm{P}}\left(t_{i}\right)+\mathrm{E}_{\mathrm{D}}\left(t_{i}\right)+\mathrm{E}_{\mathrm{L}}\left(t_{i}\right)+\Delta \mathrm{E}_{\mathrm{S}}\left(t_{i}\right)
$$

Each term in Eq. (1) will be explained in detail, but as a result, considering the intermittent energy system as a black-box, the energy balance on the system can be represented as shown in Figure 1.

Eq. (1) is normalized by dividing all terms by the maximum product energy $\left(E_{P, \max }\right)$ over all investigated time steps.

$$
N_{F}+N_{B}=N_{P}+N_{D}+N_{L}+\Delta N_{S}
$$

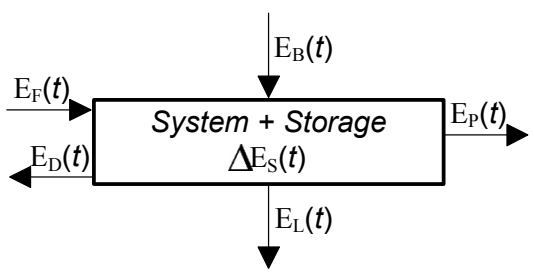

Figure 1. Energy schematic for a generic intermittent energy system.

In particular, this subsection is dedicated to the explanations of each term in Eqs. (1) and (2). A normalized product $\left(N_{P}\right)$ for an intermittent energy system over time step $t_{i}$ is defined as the ratio of the product over $t_{i}$ to the maximum product over all investigated time steps.

$\mathrm{N}_{\mathrm{P}}\left(t_{i}\right)=\frac{\mathrm{E}_{\mathrm{P}}\left(t_{i}\right)}{E_{P, \max }}$

Therefore $0 \leq \mathrm{N}_{\mathrm{P}}\left(t_{i}\right) \leq 1$.

The transient energy supplied $\left(E_{F}\right)$ by the intermittent resource can either be the energy of the intermittent resource (kinetic energy of the wind, solar irradiation) for general resource assessment studies or the output from an energy conversion system coupled to the intermittent resource (wind turbine, photovoltaic array, solar-powered cooling system, solar thermal power plant, etc) for technology assessments. As becomes evident in the following case study, defining the normalized fuel energy in terms of the maximum fuel energy $\left(E_{F, \max }\right)$ and a userdefined intermittent energy system size $\left(Z_{s y s}\right)$ facilitates the solution and allows basic trends in performance with changes in system size to be investigated.

$\mathrm{N}_{\mathrm{F}}\left(t_{i}\right)=\frac{\mathrm{E}_{\mathrm{F}}\left(t_{i}\right)}{E_{P, \text { max }}}=Z_{s y s} \times \frac{\mathrm{E}_{\mathrm{F}}\left(t_{i}\right)}{E_{F, \text { max }}}$

By definition, $0 \leq \mathrm{N}_{\mathrm{F}}\left(t_{i}\right) \leq Z_{s y s}$, one unit of normalized product energy is equal to one unit of normalized fuel energy, and $Z_{s y s}>1$ corresponds to the common case where the maximum supply is larger than the maximum demand, which allows for storage.

At each time step, the normalized transient parameter $N_{M}$ is also used to quantify the coincidence in the demand (product energy) and supply (primary fuel energy).

$\mathrm{N}_{\mathrm{M}}\left(t_{i}\right)=\mathrm{N}_{\mathrm{F}}\left(t_{i}\right)-\mathrm{N}_{\mathrm{P}}\left(t_{i}\right)$

Thus $N_{M}<0$ indicates the case where backup energy or stored energy is needed to meet the demand while $N_{M}>0$ indicates an opportunity for storage.

In this regard, three additional transient parameters are defined to investigate how storage size affects broad trends in the system's energy performance. By definition, one unit of normalized storage energy $\left(N_{S}\right)$ is equal to one unit of normalized product or fuel energy. The change in energy stored over a time step is $\Delta \mathrm{N}_{\mathrm{S}}\left(t_{i}\right)$. The maximum normalized storage magnitude, $Z_{S}$, is defined by the user and by definition $0 \leq \Delta \mathrm{N}_{\mathrm{S}}\left(t_{i}\right) \leq Z_{S}$. The magnitude of storage at the start of the simulation is also defined by the user; e.g., $\mathrm{N}_{\mathrm{S}}(t=0)=0$ for an initially empty storage. In this simple model a $100 \%$ efficient black-box storage 
technology is assumed. However the basic trends predicted by this model with variations in storage size should be valid for real storage technologies with efficiencies less than $100 \%$.

A clear differentiation is made between energy discharged $\left(E_{D}\right.$ and $N_{D}$ ) to the environment due to the normal operation of the energy system, such as the heat transfer from a condenser to the surroundings, and the energy lost $\left(E_{L}\right.$ and $\left.N_{L}\right)$ to the environment when $N_{F}>N_{P}$ and the storage is full $\left(N_{S}=Z_{S}\right)$. A normalized backup energy, $N_{B}$, quantifies the backup energy (supplied to the system) required when $N_{F}<N_{P}$ and $N_{S}=0$.

In addition to the normalized transient energy parameters, two fractions are defined to characterize the energy performance of the system. Neglecting net changes in the amount stored over the time period of interest, the fraction $(f)$ of the product demand that is met by the primary fuel supply is defined as

$$
f=\frac{\sum_{i} \mathrm{~N}_{\mathrm{F}}\left(t_{i}\right)-\sum_{i} \mathrm{~N}_{\mathrm{L}}\left(t_{i}\right)}{\sum_{i} \mathrm{~N}_{\mathrm{P}}\left(t_{i}\right)}
$$

while the fraction $(l)$ of the primary fuel supply that is lost to the environment due to full storage is defined as

$$
l=\frac{\sum_{i} \mathrm{~N}_{\mathrm{L}}\left(t_{i}\right)}{\sum_{i} \mathrm{~N}_{\mathrm{P}}\left(t_{i}\right)}
$$

Using similar logic, additional normalized parameters can be defined based on the specific energy system being modeled. Examples of two system-specific normalized size parameters can be found in Section 2.5.

\subsection{Adsorption Cycle Models}

In an adsorption cooling cycle, the mechanical compressor in the well-known vapor-compression air conditioner that is generally powered by electricity is replaced with a thermal compressor that can be driven using low-grade thermal energy like solar energy or waste heat. A schematic of an ideal simple adsorption cycle is shown in Figure 2 and operation of simple cycle is given in (Baker \& Kaftanoglu, 2007). In this figure and all other figures, positive heat transfers correspond to the direction of the arrows. The cycle is characterized by variations in the refrigerant's vapor pressure, the adsorbent bed's temperature, and adsorption capacity $(X)$, which is defined as the ratio of adsorbed refrigerant mass to adsorbent mass.

In the literature many reviews of adsorption cycles exist (Dieng \& Wang, 2001; Meunier, 2001; Sumathy, Yeung, \& Yong, 2003). Furthermore, there are several studies on adsorption cycles that investigate the effects of parameters on the system energy performance (Khan, Alam, Saha, Akisawa, \& Kashiwagi, 2007; Liu \& Leong, 2005; Sward, LeVan, \& Meunier, 2000). The present modeling work extends previously developed thermodynamic models (D. K. Baker, 2008; Baker \& Kaftanoglu, 2008) in which adsorption cooling cycles with no thermal regeneration and maximum thermal regeneration between two spatially isothermal beds are modeled. Specifically, the present work extends these previously developed adsorption cycle models by integrating them with existing solar component models in TRNSYS to yield a model of a SPAC system. The new normalized model introduced in Section 0 is used to post-process the results from seasonal-transient simulations to indicate basic trends in system energy performance as component size and operating conditions are varied. Additionally, in the previous studies only the effects of adsorbent bed's maximum temperature and heat capacitance on the system's coefficient of performance (COP) are investigated using steady-periodic simulations. In this study, the effects of the bed's maximum and minimum temperatures and heat capacities, condensation temperature, maximum cooling capacity and amount of storage are investigated using seasonal-transient simulations.

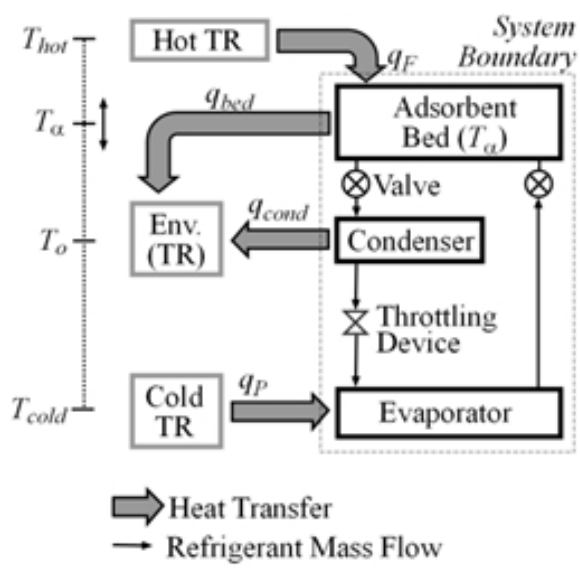

Figure 2. Schematic of an ideal simple adsorption cycle (Baker \& Kaftanoglu, 2007).

In general, the energy performance of the adsorption cycle is defined using the cycle's coefficient of performance $\left(C O P_{\text {cycle }}\right)$.

$$
C O P_{\text {cycle }}=\frac{\text { Product Heat Transfer }}{\text { Fuel Heat Transfer }}=\frac{q_{P}}{q_{F}}
$$

An ideal simple cycle only provides cooling during process $4 \rightarrow 1$ and therefore provides cooling intermittently. Additionally, $C O P_{\text {cycle }}$ of simple cycles is small compared to adsorption cycles with enhancements such as heat recovery (Wang, 2001). As a result, to meet the cooling demand using a simple cycle, large solar collector areas are needed which, in turn, significantly increase the overall cost of the system (Baker \& Kaftanoglu, 2007). To overcome these drawbacks, various modifications to the simple adsorption cycle can be implemented to increase $C O P_{\text {cycle }}$ and reduce collector costs. Modifying a cycle with heat recovery is one of the main focuses of this study.

In a heat recovery cycle, two (or more) adsorbent beds are thermally connected to each other over certain parts of the cycle. Each bed follows the same processes as the simple adsorption cycle. During heat recovery, heat is transferred from the bed being cooled (process $3 \rightarrow 1$ ) to the bed being heated (process $1 \rightarrow 3$ ). In the ideal case, the beds come to thermal equilibrium at an intermediate temperature between the minimum bed $\left(T_{\min }\right)$ and maximum bed $\left(T_{h o t}\right)$ temperatures. Therefore, the external fuel heat transfer required to heat the cold bed, $q_{F}$, is reduced and $C O P_{\text {cycle }}$ is increased (assuming the product heat transfer $q_{P}$ is constant) as per Eq. (8). The magnitude of the decrease in 
$q_{F}$ (or increase in $C O P_{\text {cycle }}$ ) is large for cycles characterized by $T_{4} \gg T_{2}$ and small for cycles characterized by $T_{4}<<T_{2}$ (Baker \& Kaftanoglu, 2007).

The thermodynamic models of adsorption cycles described in previous studies (D. K. Baker, 2008; Baker \& Kaftanoglu, 2008) are programmed in MATLAB for this research. All these models are developed to illustrate the energy performance limits of the systems. Therefore, several ideal assumptions are made such as no spatial temperature or pressure gradients inside the beds. Although the cycles are ideal, they are not reversible due primarily to heat transfers across finite temperature differences. Therefore, even the ideal cycles can have $C O P_{\text {cycle }}$ 's significantly lower than a reversible cycle.

\subsection{Solar-Thermal System Model}

In the present work, previous modeling work on adsorption cooling cycles (D. K. Baker, 2008; Baker \& Kaftanoglu, 2008) is extended to model driving the cycles using a simple solar-thermal system. This solar-thermal system consists of a solar-thermal collector, heat exchanger, circulation pump, control unit and hourly weather data as shown in Figure 3. A heat transfer fluid (HTF) loop thermally connects the collector to the adsorption cycle. The heat exchanger is driven by the hot HTF and supplies $q_{F}$ to the adsorption cooling cycle.

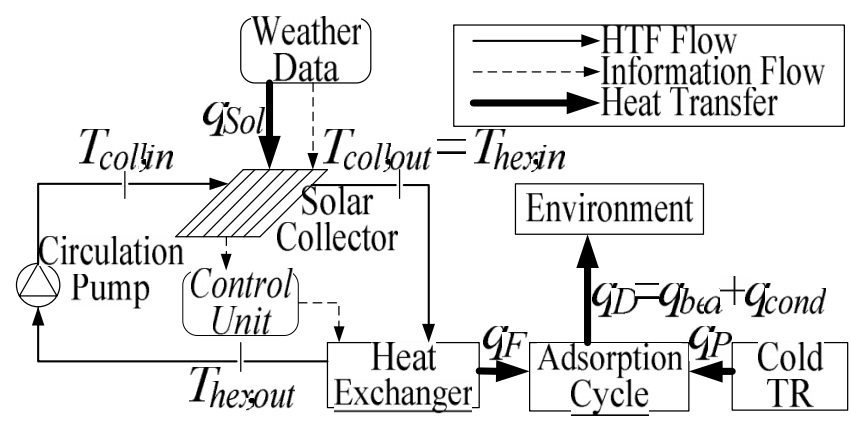

Figure 3. Solar subsystem and its integration with adsorption cycle.

TRNSYS Type 1c is used to model a flat plate collector and Type 71 to model an evacuated tube collector. The collectors' efficiencies are needed as inputs for the normalized model introduced below, but these outputs are not supplied by Types $1 \mathrm{c}$ or 71 . Therefore these efficiencies are calculated as

$$
\eta_{\text {coll }}=\frac{\dot{m}_{H T F} \times c_{p, H T F} \times\left(T_{\text {coll,out }}-T_{\text {coll,in }}\right)}{G \times A_{\text {coll }}}
$$

where $\dot{m}_{\text {HTF }}$ and $c_{p, H T F}$ are mass flow rate and specific heat of the HTF respectively, $T_{\text {coll,out }}$ and $T_{\text {coll,in }}$ are exit and inlet temperatures of collector respectively, $G$ is total radiation incident on the collector and $A_{\text {coll }}$ is the collector area.

The fuel heat transfer from the HTF loop to the adsorption cycle, $q_{F}$, is modeled using a heat exchanger (TRNSYS Type 92). All the heat transfer $q_{F}$ is assumed to leave the heat exchanger at $T_{\text {hot }}$ and a control unit (TRNSYS Type 2b) is used to maintain $q_{F}$ at $T_{h o t}$. Specifically, if $T_{\text {coll,out }}<T_{\text {hot }}$, no heat transfer will occur (heat exchanger is off), and if $T_{\text {coll,out }}>T_{\text {hot }}$, the magnitude of the fuel heat transfer is controlled such that the heat exchanger outlet temperature $\left(T_{\text {hex,out }}\right)$ is $T_{\text {hot }}$ (heat exchanger is on). The difference between the heat exchanger inlet and outlet temperatures $\left(T_{\text {hex, in }}-T_{\text {hex,out }}\right)$ determines the magnitude of $q_{F}$. To investigate the best case scenario, all thermal losses from the heat exchanger are neglected.

A circulation pump (TRNSYS Type 3d) with constant flow rate is used. In the current study, the pump operates continuously, and as with the heat exchanger, all losses are neglected.

Hourly weather data are integrated into the model using TRNSYS Type 109. The Perez sky model is selected to calculate the diffuse radiation on a tilted surface as recommended by the TRNSYS manual. From the weather data, total horizontal, incident and horizontal diffuse radiation rates are supplied to the solar-thermal collector models as well as ambient temperature $\left(T_{o}\right)$.

\subsection{Integrated Adsorption Cycle Model}

The two subsystems shown in Figures 2 and 3 are combined using TRNSYS into a single integrated system. The fuel heat transfer $q_{F}$ shown in Figure 3 is the same as the $q_{F}$ of the adsorption cycle shown in Figure 2. Two usersupplied inputs of this integrated system are maximum bed temperature $\left(T_{h o t}\right)$ and evaporator temperature $\left(T_{\text {evap }}\right)$. The condensation temperature $\left(T_{\text {cond }}\right)$ is assumed equal to either ambient $\left(T_{o}\right)$ or wet bulb $\left(T_{w b}\right)$ temperature, which corresponds to an ideal dry or wet cooling tower. In the limiting case, the adsorbent bed is cooled to the condensation temperature $\left(T_{\text {cond }}\right)$. To investigate the possible impact of a minimum bed temperature $\left(T_{\min }\right)$ that is higher than $T_{\text {cond }}$ on the energy performance due to large thermal resistances within the adsorption bed, an excess bed temperature, $\Delta T_{\text {excess }}=T_{\min }-T_{\text {cond }}$, is defined as another user input. Another key input of the system is the design heat capacity ratio, $R$ (D. K. Baker, 2008; Wang, 2001), which is the ratio of the heat capacities of the shell and HTF inside the adsorbent bed (design heat capacity) to the heat capacity of adsorbent (inherent heat capacity) as

$R=\frac{m_{H T F} \times c_{H T F}+m_{\text {shell }} \times c_{\text {shell }}}{m_{\text {ads }} \times c_{\text {ads }}}$

This integrated model can be used to run seasonaltransient simulations to investigate basic trends in and limits to the system's COP $\left(C O P_{s y s}\right)$.

$C O P_{\text {sys }}=\frac{q_{P}}{q_{\text {Sol }}}=C O P_{\text {cycle }} \times \eta_{\text {coll }}$

\subsection{Application of Normalized Model to Adsorption Cooling System}

The new normalized model introduced in Section 2.1 is applied to the integrated adsorption cooling system given in Section 2.4 for post-processing of the TRNSYS seasonaltransient simulation results. The normalized model is used to investigate how the size of the cooling system, amount of storage, and coincidence between the solar-supplied cooling and cooling demand affects the system's seasonal energy performance. In all cases this normalized model stresses simplicity over detail to quickly identify the most promising directions for more detailed research. Specifically, only a normalized storage magnitude and not type (building thermal mass, cold thermal storage tank, etc) 
is specified. At the start of each simulation the storage is assumed empty; i.e., $\mathrm{N}_{\mathrm{S}}(t=0)=0$.

Several normalized transient parameters are defined at each time step $\left(t_{i}\right)$. A normalized cooling load which is equivalent to $N_{P}$ in Section 2.1 is defined as being proportional to the temperature difference between $T_{o}$ and a reference temperature $\left(T_{\text {ref }}\right)$.

$$
\mathrm{N}_{\mathrm{P}}\left(t_{i}\right)=\frac{\mathrm{T}_{\mathrm{o}}\left(t_{i}\right)-T_{\text {ref }}}{\max \left(T_{o}-T_{r e f}\right)}
$$

Here $\max \left(T_{o}-T_{r e f}\right)$ corresponds to the time interval during the simulation with the highest $T_{o}$, and therefore maximum cooling load (demand), and $0 \leq N_{P} \leq 1$. A normalized cooling capacity which is equivalent to $N_{S}$ in Section 0 is defined as

$\mathrm{N}_{\mathrm{F}}\left(t_{i}\right)=Z_{\text {sys }} \times \frac{\mathrm{q}_{\mathrm{F}}\left(t_{i}\right) \times \mathrm{COP}_{\text {cycle }}\left(t_{i}\right)}{\max \left(q_{F} \times C O P_{\text {cycle }}\right)}$

where $Z_{s y s}$ is a user defined size of the cooling system, $q_{F}=\dot{m}_{H T F} \times c_{H T F} \times\left(T_{h e x, i n}-T_{h e x, o u t}\right)$, and $0 \leq N_{F} \leq Z_{s y s .}$ Other transient parameters $\left(N_{M}, N_{S}, N_{L}, N_{B}, Z_{S}\right)$ introduced in Section 2.1 are also directly applied to this application.

For each simulation, solar and loss fractions are defined as additional seasonal energy performance parameters as defined in Section 2.1 by Eqs. (6) and (7), respectively.

Similar to the transient and seasonal energy performance parameters, two normalized size parameters for collector area and mass of adsorbent are also defined. A normalized collector area $\left(A_{\text {coll, N }}\right)$ is defined as

$$
A_{\text {coll }, N}=\frac{\mathrm{N}_{\mathrm{P}}\left(t_{i}\right)}{\mathrm{G}_{\mathrm{N}}\left(t_{i}\right) \times \mathrm{COP}_{\mathrm{sys}}\left(t_{i}\right)}
$$

where $G_{N}\left(t_{i}\right)=G\left(t_{i}\right) / G_{r e f}$ is the normalized radiation and $G_{r e f}$ is a reference radiation level. Therefore, one unit of normalized collector area supplies one unit of normalized cooling capacity when both $G_{N}$ and $C O P_{\text {sys }}$ are one. As a normalized area, $A_{\text {coll, } N}$ can be used to compare the relative required collector area to meet the cooling load for different cases. $A_{\text {coll, } N}$ is constant in each individual case but varies among the investigated cases.

Similar to the normalized collector area, a normalized mass of adsorbent $\left(m_{a d s, N}\right)$ is defined. As an intermittent cooling cycle, the required $m_{a d s, N}$ decreases with decreasing cycle time. For simplicity in this analysis all cycle times are assumed equal. The required $m_{a d s, N}$ is inversely proportional to maximum change in adsorption capacity of the adsorbent over the half cycle $\left(\Delta X=X_{\max }-X_{\min }\right)$ during the simulation relative to that for a base case $\left(\Delta X_{b a s e}\right)$.

$$
m_{a d s, N}=\left[\frac{\max (\Delta X)}{\Delta X_{\text {base }}}\right]^{-1}
$$

Finally, to investigate the possible effects of variations in parameters on the integrated system's energy performance, in addition to the coefficient of performance of the integrated system $\left(C O P_{s y s}\right)$ given in Eq. (11), a cooling capacity $\left(q_{P}\right)$ weighted $C O P_{s y s}\left(C O P_{s y s, c l g}\right)$ for seasonal simulations is defined.

$C O P_{s y s, c l g}=\frac{\sum_{i}\left[\operatorname{COP}_{\text {sys }}\left(t_{i}\right) \times \mathrm{q}_{\mathrm{P}}\left(t_{i}\right)\right]}{\sum_{i} \mathrm{q}_{\mathrm{P}}\left(t_{i}\right)}$

\section{Analyses}

Seasonal-transient simulations were run for a system located in Antalya, Turkey, which is a large touristic city on the Turkish Mediterranean coast with long, hot and sunny summers and large cooling loads. The simulations were run using both simple and two-bed heat recovery adsorption cycle models with synthetic zeolite-water adsorbentrefrigerant pair and water as the HTF to investigate general energy performance trends when several parameters are varied. Synthetic zeolite properties from (Ben Amar, Sun, \& Meunier, 1996) and water properties from (Brissette, 2005; Schmidt, Ezekoye, Howell, \& Baker, 2005) were obtained. Additionally, the season for simulations was selected as summer for Antalya from June 1 to September 30 with 15-minute time intervals using hourly weather data.

In the normalized model, to calculate $A_{c o l l, N}, G_{r e f}$ was fixed as $1,000 \mathrm{~W} / \mathrm{m}^{2}$, which is close to the maximum radiation level of Antalya. Similarly, to calculate the cooling load $\left(E_{P}\right.$ and $\left.N_{P}\right), T_{\text {ref }}=21^{\circ} \mathrm{C}$ was selected. For $m_{\text {ads }, N}, \Delta X_{\text {base }}$ was calculated assuming a base case with $T_{\text {hot }}$ $=150^{\circ} \mathrm{C}, T_{\text {min }}=T_{\text {cond }}=30^{\circ} \mathrm{C}, P_{\text {cond }}=\mathrm{P}_{\text {sat }}\left(T_{\text {cond }}\right)$, and $P_{\text {evap }}=$ $\mathrm{P}_{\text {sat }}\left(T_{\text {evap }}\right)$ where $P_{\text {sat }}$ indicates the saturation pressure as a function of temperature. The investigated cases for seasonal-transient simulations are given in Table 1.

Table 1. Investigated cases for seasonal-transient simulations.

\begin{tabular}{|l|l|}
\hline Parameter & Investigated Values \\
\hline \hline Solar Collector Type & Flat Plate, Evacuated Tube \\
\hline Max. Bed Temp. $\left(T_{\text {hot }}\right)\left[{ }^{\circ} \mathrm{C}\right]$ & $90,120,150,180$ \\
\hline Total Radiation $(G)\left[\mathrm{W} / \mathrm{m}^{2}\right]$ & obtained from weather data \\
\hline Condensation Temp. $\left(T_{\text {cond }}\right)\left[{ }^{\circ} \mathrm{C}\right]$ & Ambient, Wet Bulb Temp. \\
\hline$\Delta T_{\text {excess }}=T_{\text {min }}-T_{\text {cond }}\left[{ }^{\circ} \mathrm{C}\right]$ & $0,10,15$ \\
\hline Ambient Temperature $\left(T_{o}\right)\left[{ }^{\circ} \mathrm{C}\right]$ & obtained from weather data \\
\hline Design Heat Capacity Ratio, $R$ & $0,3,10$ \\
\hline Evaporator Temp. $\left(T_{\text {evap }}\right)\left[{ }^{\circ} \mathrm{C}\right]$ & 10 \\
\hline
\end{tabular}

In all simulations, the energy performance characteristics of either a flat plate or evacuated tube nontracking solar-thermal collector located on the roof of the Mechanical Engineering Department at the Middle East Technical University were used. The energy performance characteristics for these collectors were obtained from their manufacturers. To investigate the effect of using a dry rather than wet cooling tower due to concerns over water consumption, the condensation temperature was set equal to either $T_{o}$ (dry cooling tower) or $T_{w b}$ (wet cooling tower). The investigated values of $R$ correspond to the theoretical limit (0), state-of-the-art design (3) and typical design (10) (Wang, 2001).

\section{Results}

The effects of $Z_{S}$ on $f$ and $l$ were investigated and representative results for $Z_{s y s}=1$ are given in Figure 4. Note if any net changes in storage between the start and end of a simulation are neglected, $1-f$ is proportional to the required normalized backup power. For $Z_{S}>10$ and $Z_{s y s}=$ 
1 , as $T_{\text {hot }}$ increases $l$ decreases and becomes zero at smaller $Z_{S}$, and $f$ also decreases but not significantly. Systems with evacuated tube collectors result in higher $f$ and $l$ values than systems with flat plate collectors except when $T_{\text {hot }}=90^{\circ} \mathrm{C}$. At approximately $90^{\circ} \mathrm{C}$ the flat plate and evacuated tube collector efficiencies are comparable to each other, but for $T_{h o t}>90^{\circ} \mathrm{C}$ the efficiency of the evacuated tube collector is higher than the efficiency of flat plate collector. When simple and heat recovery cycles are compared, $f$ and $l$ do not change significantly. Additionally, using a wet cooling tower increases $f$ when compared to a dry cooling tower because the temperature swing between $T_{h o t}$ and $T_{w b}$ is higher than between $T_{h o t}$ and $T_{o}$ which results in higher $\Delta X$ and correspondingly higher $q_{F}$. The effect of cooling tower type on $l$ is different for flat plate and evacuated tube collectors. For wet cooling towers $l$ is larger when flat plate collectors are used while for dry cooling towers $l$ is larger when evacuated tube collectors are used except when $Z_{S}=$ 0 . Reducing $R$ increases $f$ and reduces $l$ as lower $R$ means less energy is stored due to the design heat capacity. Moreover, as $\Delta T_{\text {excess }}$ increases, $f$ decreases for all investigated $Z_{S}$ and $l$ increases for all investigated $Z_{S} \geq 3$. Changes in $f$ and $l$ are more significant when $R$ changes from 0 to 10 than when $\Delta T_{\text {excess }}$ changes from 0 to $10^{\circ} \mathrm{C}$. It is worth noting that for the flat plate collector and $T_{\text {hot }}=$ $180^{\circ} \mathrm{C}, f$ and $l$ are zero for all $Z_{S}$ since the modeled flat plate collector cannot operate at $T_{\text {hot }}=180^{\circ} \mathrm{C}$ (which is above its stagnation temperature) and consequently $N_{F}=0$.

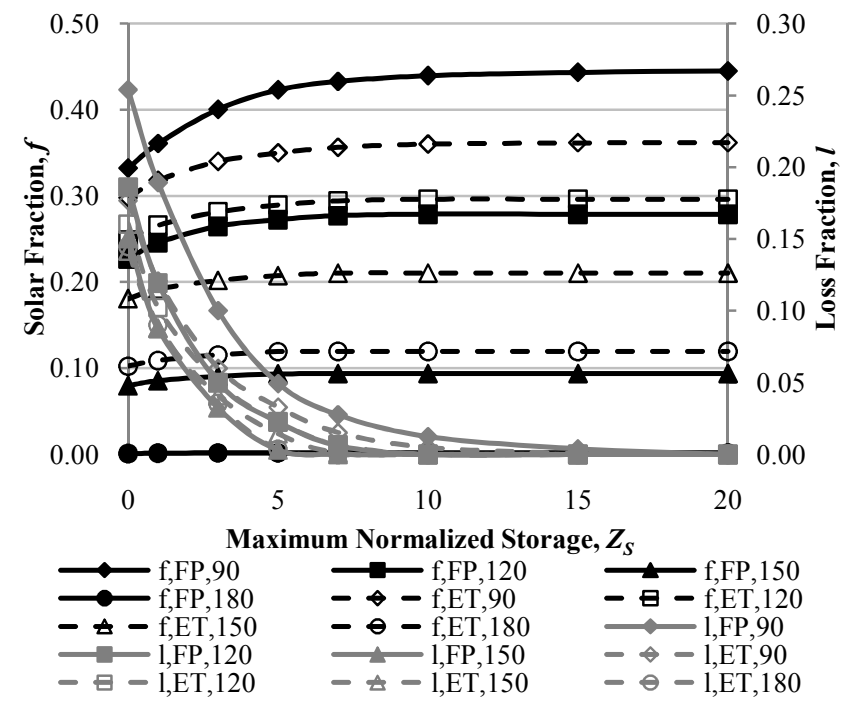

Figure 4. f and l vs. $Z_{S}$ for transient simulations and various collector types and $T_{\text {hot }}$. (simple cycle; $R=10 ; Z_{\text {sys }}=1$; wet cooling tower; $\Delta T_{\text {excess }}=10^{\circ} \mathrm{C}$; Legend: fll,CC,HH where $C C=$ collector type $: F P=$ flat plate $; E T=$ evacuated tube; $\left.H H=T_{\text {hot }}\left({ }^{\circ}\right)\right)$.

When the effects of $Z_{s y s}$ on $f$ and $l$ are compared, as $Z_{s y s}$ increases $f$ increases and $l$ decreases as seen in Figure 5 . Only a limited number of cases among the investigated cases are shown in Figure 5 due to space limitations. As $Z_{s y s}$ increases the increase in $f$ becomes less significant. Therefore, trade-off calculations between the size and performance of the intermittent systems are available through this analysis since the benefit of increasing $Z_{s y s}$ by a fixed increment decays as $Z_{s y s}$ increases. $f$ values for each $Z_{\text {sys }}$ also reach asymptotically a value as $Z_{s}$ increases. Therefore, there is also an optimum limit for storage size. Additionally, as $Z_{s y s}$ increases changes in $l$ become more significant as $Z_{S}$ increases. As with the $Z_{s y s}=1$ cases, $f$ and $l$ of simple and heat recovery cycles do not differ significantly, and $f$ and $l$ decrease as $\Delta T_{\text {excess }}$ increases from 0 to $10^{\circ} \mathrm{C}$. When cases with $R=0$ are compared to cases with $R=10$ while $Z_{s y s}$ is varying, $f$ and $l$ are lower for $R=$ 10 cases. For those cases, the effects of $R$ are more significant on the simple cycle than the heat recovery cycle since heat recovery allows a portion of energy stored due to the design heat capacity to be recovered.

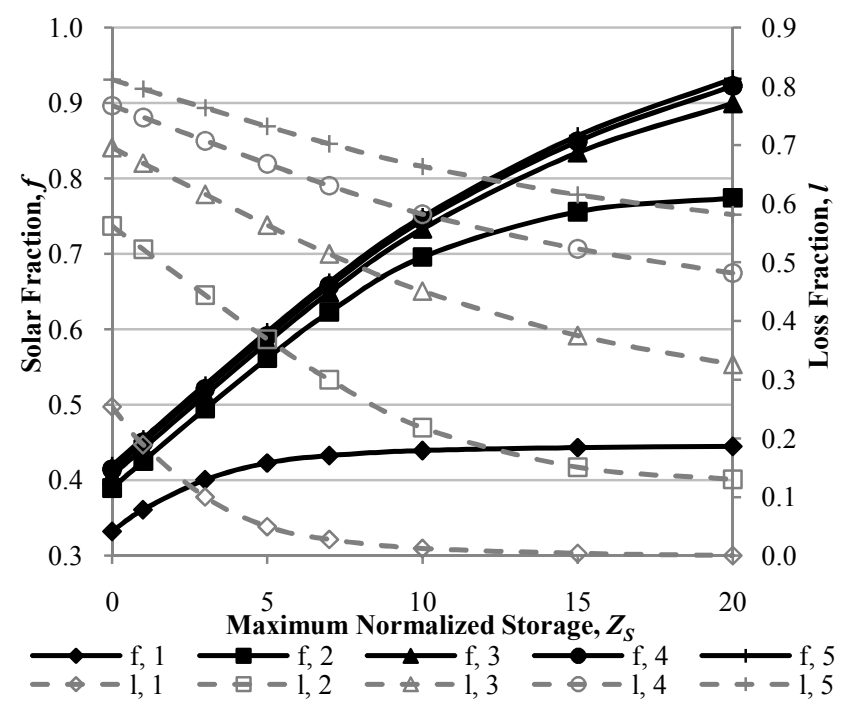

Figure 5. f and $l$ vs. $Z_{S}$ for transient simulations and various $Z_{\text {sys }}$ (flat plate collector; wet cooling tower; simple cycle; and $R=10, T_{\text {hot }}=90^{\circ} \mathrm{C}, \Delta T_{\text {excess }}=10^{\circ} \mathrm{C}$; Legend: $\left.f / l, Z_{\text {sys }}\right)$.

Representative results for $A_{\text {coll, } N}$ are given in Figure 6. In all cases, $A_{\text {coll, } N}$ has minimum values around $T_{\text {hot }}=90^{\circ} \mathrm{C}$ for the flat plate collector and around $T_{h o t}=120^{\circ} \mathrm{C}$ for the evacuated tube collector, and it does not change significantly with $\Delta T_{\text {excess. }}$. These minimum values result from the competing effects of collector efficiency decreasing and $C O P_{\text {cycle }}$ increasing with $T_{\text {hot }}$. For the range of conditions investigated, the parameters listed in order from the strongest to weakest effect on $A_{c o l l, N}$ are collector type, adsorption cycle type, cooling tower type and $R$. The required $A_{\text {coll, } N}$ is higher in systems with flat plate collectors than systems with evacuated tube collectors as seen in Figure 6. Additionally, it can be observed from Figure 6 that using a heat recovery cycle and/or a wet cooling tower results in smaller $A_{\text {coll,N }}$. Lastly, in contrast to $C O P_{s y s}$ (or $\left.C O P_{s y s, c l g}\right), A_{\text {coll, } N}$ increases with increasing $R$.

Required $m_{a d s, N}$ decreases as $T_{h o t}$ increases and this decrease is nearly linear for $T_{\text {hot }}>120^{\circ} \mathrm{C}$ as shown in Figure 7. As expected from $C O P_{s y s, c l g}$ results, the required $m_{a d s, N}$ increases with $\Delta T_{\text {excess }}$, and systems with wet cooling towers require smaller $m_{a d s, N}$ than systems with dry cooling towers. Although not shown in Figure 7 due to space limitations, the required $m_{a d s, N}$ is independent of the adsorption cycle type, collector type or $R$ since $m_{a d s, N}$ is only a function of $\Delta X=X_{\max }-X_{\min }=\mathrm{X}\left(T_{\min }, T_{\text {evap }}\right)-\mathrm{X}\left(T_{\text {hot }}, T_{\text {cond }}\right)$.

Seasonal-transient simulations were run not only for the simple cycle but also for the heat recovery cycle. A total of 96 cases were investigated, and in these transient simulations, $C O P_{s y s, c l g}$, given by Eq. (16), were compared among the investigated cases given in Table 1.

Representative simulation results are given in Figure 8. The evacuated tube collector gave higher $C O P_{s y s, c l g}$ than the 
flat plate collector. Moreover, as $R$ increases, $C O P_{s y s, c l g}$ decreases significantly in all cases and adding heat recovery increases the efficiency by a factor of approximately two relative to the simple cycle.

The effect of using ideal dry $\left(T_{\text {cond }}=T_{o}\right)$ versus ideal wet $\left(T_{c o n d}=T_{w b}\right)$ cooling towers are shown in Figure 8 . In all cases, wet cooling towers gave higher efficiencies than dry cooling towers. When the adsorbent bed is not cooled down to the condensation temperature (i.e., $\Delta T_{\text {excess }}>0$ ), $C O P_{\text {sys,clg }}$ increases. Additionally, as $\Delta T_{\text {excess }}$ increases, $C O P_{\text {sys,clg }}$ increases except in one case. This exception was observed when using a dry cooling tower with $T_{h o t}=90^{\circ} \mathrm{C}$ and $R=10$ regardless of the collector type and adsorption cycle. In all cases, the differences in $C O P_{s y s, c l g}$ due to changes in $T_{\text {cond }}$ and $R$ diminish as $T_{\text {hot }}$ increases. As a final note, when an evacuated tube collector is used, $C O P_{s y s, c l g}$ has a peak value near $T_{h o t}=120^{\circ} \mathrm{C}$.

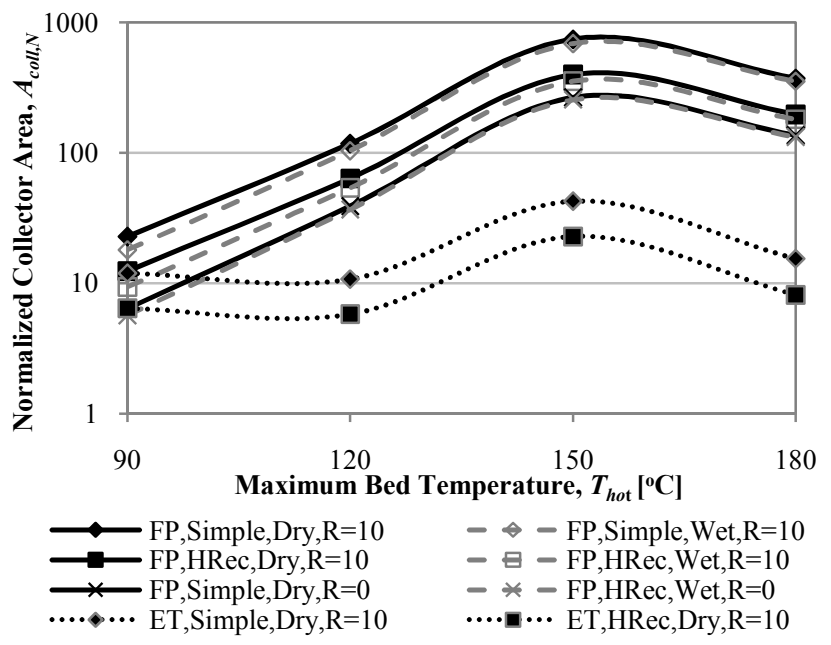

Figure 6. $A_{\text {coll,N }}$ vs. $T_{\text {hot }}\left[{ }^{\circ} \mathrm{C}\right]$ for transient simulations and different collector, adsorption cycle, cooling tower types and $R$ ( $\triangle T_{\text {excess }}=0^{\circ} C$; Legend: CC,AAAA,DDD, $R$ where $C C=$ collector type: $F P=$ flat plate; $E T=$ evacuated tube; $A A A A=$ cycle: HRec $=$ heat recovery; Simple = simple; $D D D=$ cooling tower type: Dry or Wet).

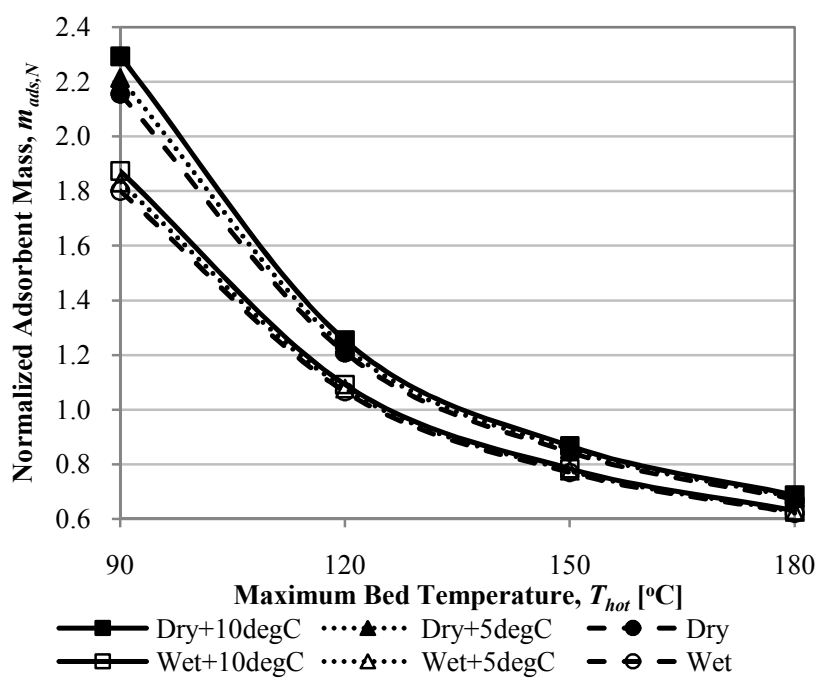

Figure 7. $m_{a d s, N}$ vs. $T_{\text {hot }}\left[{ }^{\circ} \mathrm{C}\right]$ for transient simulations and different cooling towers and $T_{\min }$ (evacuated tube collector and $R=10$; Legend: Dry or Wet cooling tower $\left.+\Delta T_{\text {excess }}\left[{ }^{\circ} \mathrm{C}\right]\right)$.

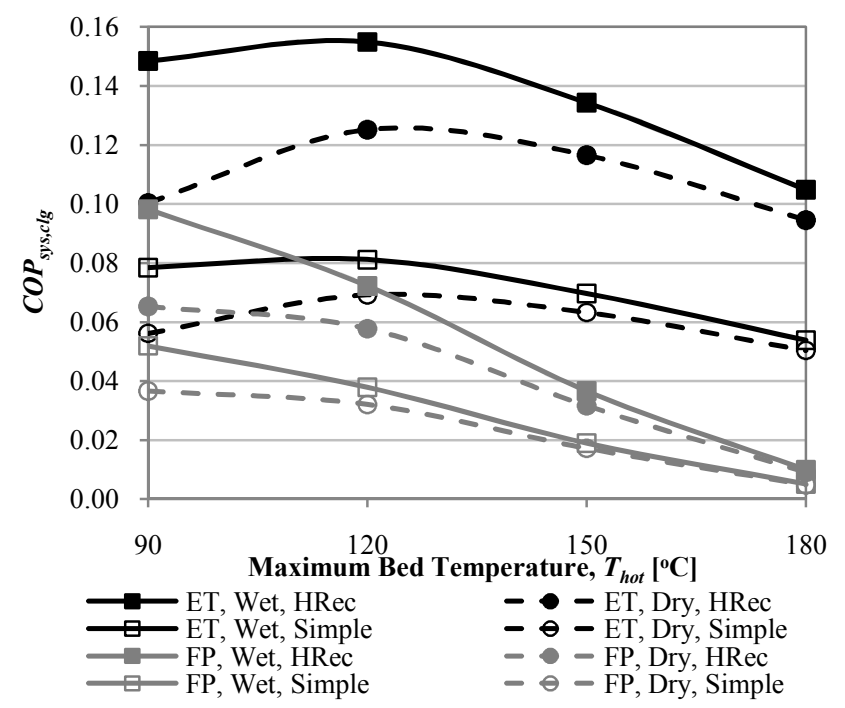

Figure 8. Collector, cooling tower and adsorption cycle comparisons on $C O P_{\text {sys,clg }}$ vs. $\left.T_{\text {hot }}{ }^{\circ} \mathrm{C}\right]$ for transient simulations $\left(R=10\right.$ and $\Delta T_{\text {excess }}=10^{\circ} \mathrm{C}$; Legend: $F P=$ flat plate collector; $E T=$ evacuated tube collector; Dry and Wet refer to cooling tower type; HRec = heat recovery cycle; Simple $=$ simple cycle).

\section{Conclusions}

A new normalized model and its application to a SPAC system are presented. The normalized model is kept simple and is appropriate for initial feasibility and sizing studies for a wide range of intermittent energy systems. The model development also provides a framework for extending the model to capture Second Law, economic and other aspects.

For the application of the normalized model, transientseasonal simulations using hourly weather data for the city of Antalya which is on the Mediterranean coast of Turkey were performed. For simplicity, ideal systems are assumed in the analysis to investigate limits to the energy performance, general trends and relative values. Therefore, absolute values should not be inferred from these results. The results of the normalized model for the investigated conditions of a SPAC system indicate that backup power is always necessary (i.e., $f<1$ ) to meet the cooling demand. On the other hand, the amount of the backup power can be reduced significantly by using an adsorption cycle with thermal regeneration (heat recovery adsorption cycle), evacuated tube collector and a larger storage unit (i.e., higher $Z_{S}$ ).

Moreover, simulation results suggest that a synthetic zeolite-water adsorbent-refrigerant pair requires a relatively high $T_{\text {hot }}$ that cannot be reached easily using flat plate collectors due to their lower stagnation temperatures. This result indicates the necessity of using evacuated tube collectors for the investigated system. To have the smallest collector area (smallest $A_{\text {coll, } N}$ ) among the investigated cases, the system should be operated at a low $T_{\text {hot }}$ which, in return, requires large $m_{a d s, N}$. In contrast, to have minimum $m_{a d s, N}, \Delta X$ should be high which corresponds to high $T_{\text {hot }}$ values since $T_{\text {cond }}$ (or $T_{\min }$ ) is fixed by the weather data. Additionally, to have smaller backup power (higher $f$ ), $A_{\text {coll }, N}$ or $m_{a d s, N}$ (or to have higher $C O P_{s y s, c l g}$ ), wet cooling towers are preferred over dry cooling towers if water consumption is not a problem.

For the investigated application of the introduced normalized model, among the investigated cases, evacuated tube collectors and wet cooling towers should be preferred 
in an adsorption cycle with thermal regeneration to have high $C O P_{\text {sys,clg }}$ and a small system size. For the other parameters analyzed such as the system's physical constraints and ambient conditions, there is no single best operating condition for the modeled SPAC system.

Future work will focus on expanding the newly developed normalized model by introducing new parameters including exergy ratios to attain the second law perspective of the energy systems and applying the model to the adsorption cycles with other adsorbent-refrigerant pairs (e.g., silica gel-water, activated carbon-ammonia) and to an ideal thermal wave adsorption cycle model (Sumathy, et al., 2003).

\section{Acknowledgments}

This work is supported by The Scientific \& Technological Research Council of Turkey (TUBITAK) project 105M244. The authors would also like to thank Dr. Cemil Yamalı, İsmail Solmuş and Ahmet Çağlar for their contributions to the experimental parts of this project that motivated this modeling work.

\begin{tabular}{ll}
\multicolumn{2}{l}{ Nomenclature } \\
$A$ & Area \\
$c$ & Constant specific heat \\
$E$ & Energy \\
$f$ & Fraction of demand met by supply \\
$G$ & Solar radiation \\
$l$ & Fraction of lost energy to environment \\
$m$ & Mass \\
$\dot{m}$ & Mass flow rate \\
$N$ & Normalized parameter \\
$P$ & Pressure \\
$q$ & Heat transfer \\
$R$ & Heat capacity ratio \\
$t$ & Time \\
$T$ & Temperature \\
$X$ & Adsorption capacity \\
$Z$ & Size of the system/storage
\end{tabular}

\section{Greek}

$\eta \quad$ Thermal efficiency

$\begin{array}{ll}\text { Subscripts } \\ \text { ads } & \text { Adsorbent } \\ B & \text { Backup } \\ \text { clg } & \text { Cooling } \\ \text { coll } & \text { Solar thermal collector } \\ \text { cond } & \text { Condenser or condensation } \\ D & \text { Discharge } \\ \text { evap } & \text { Evaporator or evaporation } \\ F & \text { Fuel/Supply } \\ \text { hex } & \text { Heat exchanger } \\ \text { hot } & \text { Maximum of adsorbent bed } \\ i & \text { Time instant } \\ \text { in } & \text { Inlet } \\ L & \text { Loss } \\ M & \text { Match factor } \\ P & \text { Product/Demand } \\ o & \text { Ambient } \\ \text { out } & \text { Outlet } \\ \text { ref } & \text { Reference } \\ S & \text { Storage } \\ \text { sat } & \text { Saturation } \\ \text { shell } & \text { Adsorbent bed shell }\end{array}$

$\begin{array}{ll}\text { Sol } & \text { Solar } \\ \text { sys } & \text { System } \\ \text { tot } & \text { Total } \\ w b & \text { Wet bulb }\end{array}$

\section{Abbreviations}

COP Coefficient of performance

ET Evacuated tube collector

FP Flat plate collector

HRec Heat recovery adsorption cooling cycle

HTF Heat transfer fluid

SPAC Solar-thermal powered adsorption cooling

TR Thermal reservoir

\section{References}

Baker, D. K. (2008). Thermodynamic limits to thermal regeneration in adsorption cooling cycles. International Journal of Refrigeration, 31(1), 55-64.

Baker, D. K., \& Kaftanoglu, B. (2007). Limits to the Thermodynamic Performance of $A$ Thermal Wave Adsorption Cooling Cycle. Paper presented at the International Conference on Heat Transfer, Fluid Mechanics and Thermodynamics (HEFAT), Sun City, South Africa.

Baker, D. K., \& Kaftanoglu, B. (2007). Predicted Impact of Collector and Zeolite Choice on the Thermodynamic and Economic Performance of a Solar-Powered Adsorption Cooling System. Experimental Heat Transfer, 20(2), 103 - 122.

Baker, D. K., \& Kaftanoglu, B. (2008). Trends in COP for Adsorption Cooling Cycles with Thermal Regeneration and Finite Number of Beds. Paper presented at the Energy Sustainability 2008, Jacksonville, Florida, USA.

Baker, J. (2008). New technology and possible advances in energy storage. Energy Policy, 36(12), 4368-4373.

Battaglini, A., Lilliestam, J., Haas, A., \& Patt, A. (2009). Development of SuperSmart Grids for a more efficient utilisation of electricity from renewable sources. Journal of Cleaner Production, 17(10), 911-918.

Ben Amar, N., Sun, L. M., \& Meunier, F. (1996). Numerical analysis of adsorptive temperature wave regenerative heat pump Applied Thermal Engineering, $16,405-418$

Benitez, L. E., Benitez, P. C., \& van Kooten, G. C. (2008). The economics of wind power with energy storage. Energy Economics, 30(4), 1973-1989.

Brissette, F. (2005). Thermodynamic properties of water [MatLab]. Montreal: Université du Québec.

Cruickshank, C. A. (2009). Evaluation of a Stratified MultiTank Thermal Storage for Solar Heating Applications. Ph.D. Dissertation, Queen's University, Ontario.

Denholm, P., \& Margolis, R. M. (2007). Evaluating the limits of solar photovoltaics (PV) in electric power systems utilizing energy storage and other enabling technologies. Energy Policy, 35(9), 4424-4433.

Dieng, A. O., \& Wang, R. Z. (2001). Literature review on solar adsorption technologies for ice-making and airconditioning purposes and recent developments in solar 
technology. Renewable and Sustainable Energy Reviews, 5(4), 313-342.

Divya, K. C., \& Østergaard, J. (2009). Battery energy storage technology for power systems--An overview. Electric Power Systems Research, 79(4), 511-520.

Duic, N., \& da Graça Carvalho, M. (2004). Increasing renewable energy sources in island energy supply: case study Porto Santo. Renewable and Sustainable Energy Reviews, 8(4), 383-399.

Ibrahim, H., Ilinca, A., \& Perron, J. (2008). Energy storage systems-Characteristics and comparisons. Renewable and Sustainable Energy Reviews, 12(5), 1221-1250.

Jebaraj, S., \& Iniyan, S. (2006). A review of energy models. Renewable and Sustainable Energy Reviews, 10(4), 281-311.

Kélouwani, S., Agbossou, K., \& Chahine, R. (2005). Model for energy conversion in renewable energy system with hydrogen storage. Journal of Power Sources, 140(2), 392-399.

Khan, M. Z. I., Alam, K. C. A., Saha, B. B., Akisawa, A., \& Kashiwagi, T. (2007). Study on a re-heat two-stage adsorption chiller - The influence of thermal capacitance ratio, overall thermal conductance ratio and adsorbent mass on system performance. Applied Thermal Engineering, 27(10), 1677-1685.

Knob, P., Rüther, R., Jardim, C., \& Beyer, H. G. (2004). Investigating the Peak Demand Reduction Capability of PV: A Case Study in Florianopolis, South Brazil. Paper presented at the 19th European Photovoltaic Solar Energy Conference, Paris, France.

Koomey, J., \& Brown, R. E. (2002). The role of building technologies in reducing and controlling peak electricity demand. Berkeley: Lawrence Berkeley National Laboratory, University of California.

Korpaas, M., Holen, A. T., \& Hildrum, R. (2003). Operation and sizing of energy storage for wind power plants in a market system. International Journal of Electrical Power \& Energy Systems, 25(8), 599-606.

Korpås, M. (2004). Distributed Energy Systems with Wind Power and Energy Storage. Ph.D. Dissertation, Norwegian University of Science and Technology, Trondheim.

Lenzen, M. (2010). Current State of Development of Electricity-Generating Technologies: A Literature Review. Energies, 3(3), 462-591.

Liu, Y., \& Leong, K. C. (2005). The effect of operating conditions on the performance of zeolite/water adsorption cooling systems. Applied Thermal Engineering, 25(10), 1403-1418.
Lund, H., \& Salgi, G. (2009). The role of compressed air energy storage (CAES) in future sustainable energy systems. Energy Conversion and Management, 50(5), 1172-1179.

Manolakos, D., Papadakis, G., Papantonis, D., \& Kyritsis, S. (2004). A stand-alone photovoltaic power system for remote villages using pumped water energy storage. Energy, 29(1), 57-69.

Meunier, F. (2001). Adsorptive cooling: a clean technology. Clean Technologies and Environmental Policy, 3(1), 820.

Moslehi, K., \& Kumar, R. (2010). Smart Grid - A Reliability Perspective. Paper presented at the IEEE PES Conference on "Innovative Smart Grid Technologies", Gaithersburg, Maryland.

Myers, K. S., Klein, S. A., \& Reindl, D. T. (2010). Assessment of High Penetration of Photovoltaics on Peak Demand and Annual Energy Use. Madison: University of Wisconsin.

Schmidt, P. S., Ezekoye, O., Howell, J. R., \& Baker, D. K. (2005). Thermodynamics: an integrated learning system: Wiley.

Sharma, A., Tyagi, V. V., Chen, C. R., \& Buddhi, D. (2009). Review on thermal energy storage with phase change materials and applications. Renewable and Sustainable Energy Reviews, 13(2), 318-345.

Sumathy, K., Yeung, K. H., \& Yong, L. (2003). Technology development in the solar adsorption refrigeration systems. Progress in Energy and Combustion Science, 29(4), 301-327.

Sward, B. K., LeVan, M. D., \& Meunier, F. (2000). Adsorption heat pump modeling: the thermal wave process with local equilibrium. Applied Thermal Engineering, 20(8), 759-780.

TEİAȘ. (2007). The Distribution of Gross Electricity Generation by Primary Energy Resources and The Electric Utilities in Turkey. Ankara: Turkish Electricity Transmission Co. (TEIAS).

TEİAŞ. (2009). Turkish Electrical Energy 10-Year Generation Capacity Projection. Ankara: Turkish Electricity Transmission Co. (TEIAS).

Vosen, S. R., \& Keller, J. O. (1999). Hybrid energy storage systems for stand-alone electric power systems: optimization of system performance and cost through control strategies. International Journal of Hydrogen Energy, 24(12), 1139-1156.

Wang, R. Z. (2001). Performance improvement of adsorption cooling by heat and mass recovery operation. International Journal of Refrigeration, 24(7), 602-611. 